\title{
Comparing the Effects of COVID-19 on ETAC and EAC Programs at a Re- gional Comprehensive University
}

\section{Dr. Andrew Ritenour, Western Carolina University}

Andrew Ritenour is currently an Assistant Professor in the School of Engineering + Technology at Western Carolina University (WCU). Prior to joining WCU in 2018, he spent a decade in industry managing and developing innovative technologies across a broad spectrum of applications: high voltage transistors for energy-efficient power conversion, radio frequency (RF) surface acoustic wave (SAW) filters for mobile phones, and flexible paper-like displays for e-readers. He holds 30 patents related to semiconductor devices and microfabrication and has published in IEEE and AIP journals and conferences. His current research interests include instrumentation for combustion science, novel methods for environmental remediation, and microelectronics including surface acoustic wave (SAW) devices. In addition to teaching in the field of electrical engineering, he coordinates the senior engineering capstone program which is a multidisciplinary, two-semester course sequence with projects sponsored by industrial partners. Within this role, he focuses on industrial outreach and the teaching and assessment of professional skills. He received his Ph.D. and S.M. degrees from MIT in 2007 and 1999, respectively, and a B.S.E.E. degree from the University of Virginia in 1997.

\section{Dr. Wesley L. Stone, Western Carolina University}

Dr. Wes Stone is professor in the School of Engineering + Technology at Western Carolina University in Cullowhee, NC. He earned his bachelors degree from the University of Texas at Austin, masters degree from Penn State, and PhD from Georgia Tech, all in Mechanical Engineering. His research interests include manufacturing processes, quality techniques, and outdoor gear design/testing. He also serves as the program director for Engineering Technology and is Faculty Liaison to the Outdoor Industry.

\section{Dr. Chip W. Ferguson, Western Carolina University}

Chip Ferguson is the Associate Dean of the College of Engineering and Technology and Professor of Engineering and Technology at Western Carolina University.

\section{Dr. Hayri Sezer, Western Carolina University}

Dr. Sezer is an assistant professor of thermal and fluid sciences at Western Carolina University in department of engineering and technology. Dr. Sezer received his B.Sc. degree in physics engineering (2005) and M. Sc. in defence technologies (Material Science) from Istanbul Technical University (2009), and he got his Ph.D. degree in mechanical and aerospace engineering from West Virginia University (2014). His research interest is in the field of computational fluid dynamics and its application in combustion, heat and mass transfer, fluid flow, wild land fires, renewable energy technologies, fire dynamics and electrochemical energy storage and conversion devices (Fuel cells and Batteries). He has developed and refined 1D and 3D dynamic solvers for species transport, heat transfer, electrochemical reactions (adsorption and desorption), impedance, polarization and electrical potential for solid oxide fuel cells (SOFCs) and sodium sulphur batteries (Na-S). He also has developed a novel model to predict the nickel coarsening in high temperature SOFCs based on electro-migration. His current research is related to computational modeling of liquid atomization, drag coefficient of complex geometries, combustion, fire dynamics and heat transfer mechanisms of 3D direct laser metal sintering.

\section{Dr. Yang Zhang, Western Carolina University}

Dr. Yang Zhang is an Assistant Professor in the School of Engineering + Technology at Western Carolina University. Dr. Zhang received his B.S. in Safety Engineering at Dalian Jiaotong University in China. Then Dr. Zhang got his M.S. and Ph.D. in Industrial Engineering at Texas Tech University. Dr. Zhang's educational focus is concentrating on Engineering Technology instruction with innovative methods. 


\section{ASEE ANNUAL CONFERENCE}

Virtual Meeting | July 26-29, 2021 | Pacific Daylight Time

\section{Dr. AMM Nazmul Ahsan, Western Carolina University}

Dr. Ahsan is currently an Assistant Professor in the School of Engineering and Technology at Western Carolina University. Dr. Ahsan achieved his Ph.D. degree in Industrial and manufacturing Engineering from North Dakota State University in 2019. Before that he completed his Master's degree in Industrial Engineering and Management from the same university. His teaching and research interest includes digital design and 3D modeling, advanced manufacturing, CAD/CAM, automated systems, additive Manufacturing/3D printing, heterogeneous light weight porous structure design and manufacturing, and bio-printing. 


\title{
Comparing the Effects of COVID-19 on ETAC and EAC Programs at a Regional Comprehensive University
}

\begin{abstract}
Western Carolina University (WCU) is a regional comprehensive university in a rural part of western North Carolina. The School of Engineering and Technology at WCU houses four undergraduate, residential programs - Electrical Engineering (EE), Electrical and Computer Engineering Technology (ECET), Engineering with Mechanical and Electrical Power Concentrations (BSE), and Engineering Technology (ET). Two of the programs are primarily electrical in nature - EE and ECET, while the other two are primarily mechanical - BSE and ET. The EE and BSE programs are accredited by the Engineering Accreditation Commission (EAC) of ABET; the ECET and ET programs are accredited by the Engineering Technology Accreditation Commission (ETAC). The school has built curricula that integrate all four programs into five common courses, designated the project-based learning (PBL) sequence. Thus it is common for a faculty member to teach a PBL course with students from all four programs, integrated into interdisciplinary teams. The balance of theory and application varies amongst the programs: the two engineering programs (EE and BSE) have a stronger emphasis on theory and design, while the two engineering technology programs (ECET and ET) place more weight on application. Given this difference in emphasis, the impact of disruptions such as COVID-19 to engineering and engineering technology programs might be different.

In the Spring semester of 2020, academic institutions across the United States significantly adjusted content delivery as a result of COVID-19. Adjustments to course delivery have continued into the Fall semester of 2020 and Spring semester of 2021. These adjustments have affected many people on every campus. This paper presents the impact of changes due to COVID-19 on teaching and learning for students and faculty in the School of Engineering and Technology. Data were collected from students in the form of a survey that explored the impact of COVID-19 in the classroom. Perceptions of learning in three course formats (face-to-face, hybrid, online) and two online delivery methods (asynchronous, synchronous) offered in 2020 were surveyed. Student perception of instructor behavior and student expectations of their instructor during the pandemic were also assessed. This paper evaluates the differences in those impacts for engineering (EAC) and engineering technology (ETAC) programs.
\end{abstract}

\section{Introduction}

The School of Engineering and Technology at Western Carolina University (WCU) houses four undergraduate, residential programs - Electrical Engineering (EE), Electrical and Computer Engineering Technology (ECET), Engineering with Mechanical and Electrical Power Concentrations (BSE), and Engineering Technology (ET). Two of the programs are primarily electrical in nature - EE and ECET, while the other two are primarily mechanical - BSE and ET. The EE and BSE programs are accredited by the Engineering Accreditation Commission (EAC) of ABET; the ECET and ET programs are accredited by the Engineering Technology Accreditation Commission (ETAC). 
Combining EAC and ETAC programs within the same department is a unique feature of WCU which results in close coupling between the more theoretical engineering programs and the more applied engineering technology programs. EAC and ETAC students participate in the same Project-Based Learning (PBL) course sequence which spans all four years of the undergraduate program. Faculty also teach in both the engineering and engineering technology programs further strengthening the cohesiveness of these programs [1].

In early 2020, academic institutions across the world started to feel the impact of COVID-19 and its effects have continued into 2021 [2], [3]. In response to COVID-19, WCU transitioned to online learning in March 2020 and continued in this format until the end of the Spring semester. For Fall 2020 courses, three modalities were offered: face-to-face, hybrid, and online. In the face-to-face modality, courses are delivered in the traditional format with in-person, on-campus classes. In the hybrid modality, courses are delivered through both in-person and online methods. This structure is flexible and allows the instructor to adapt course delivery to best achieve learning outcomes. As an example, an instructor may meet with half of the class in-person on Monday, while the other students participate online. On Wednesday, the two groups would be reversed. In another example, lectures may be delivered online and lab exercises/experiential learning might occur in person. The hybrid format also includes cases in which lab kits are provided to students to allow for hands-on, off-campus experiential learning. The third modality is online instruction in which all course activities are delivered in a virtual environment. Several studies have compared and contrasted the different modalities and offered findings either supporting or refuting student preference and engagement in each but none were conducted during a pandemic [4-8].

The unique structure of the School of Engineering and Technology at WCU, and specifically the integration of EAC and ETAC programs in a single academic unit, provides the basis for investigating the relative impact of COVID-19 on both groups of students.

\section{Objective}

COVID-19 has forced higher education institutions to implement new learning modalities across all degree programs. As with many other fields of study, engineering instruction relies heavily on labs, project-based courses, and other experiential modes of learning. Decisions regarding course modality were made to ensure that learning outcomes are still achieved and were based on presumed student learning preferences. However, to guide future decisions regarding course modality, and specifically optimize course delivery to best achieve learning objectives, the students' perception of learning in various formats must be considered. The objective of this work was to survey EAC and ETAC student opinion on their learning experiences in the COVD19 era (Spring and Fall 2020) to provide guidance for course delivery in future semesters, and specifically identify whether the two groups showed any divergent opinions. Survey results were shared with the faculty to provide timely feedback in a rapidly changing learning environment.

The survey was only administered to students in WCU's four residential, undergraduate engineering and engineering technology programs. While this analysis applies specifically to these programs, it is expected that lessons learned here could be reasonably extended to other institutions that rely heavily on PBL to achieve their learning objectives. 


\section{Procedure}

A survey with approximately 40 questions was sent to all undergraduate students enrolled in degree programs within the School of Engineering and Technology. These questions were developed in coordination with the Office of Institutional Planning and Effectiveness at WCU and included several questions derived from the National Survey of Student Engagement COVID Module, which was to be subsequently administered across the entire student body [9]. Students were asked to self-identify their major and year within the program (freshman, sophomore, junior, senior). The survey covered a broad range of topics including course modality, support services, facilities, safety, and instructor attitude and behavior. This paper focuses on a subset of those questions related to student opinions on learning modalities and their instructors. The response type varied by question. To better compare group means, responses were coded with numerical values. For example, responses given in a Likert scale (strongly agree, agree, disagree, strongly agree) were coded $(4,3,2,1)$. Other responses that represented a range or spectrum were similarly coded. During the initial data analysis, it was clear that the student's year in the program was a significant factor. For the purposes of analysis, respondents were grouped by category of their degree program (ETAC, EAC) and class standing (LC= lower class: freshman and sophomore, UC= upper class: junior and senior). Students selected their class standing, so these data are based on the student's perception of their progress rather actual credits towards degree requirements. Mean responses for these groups were analyzed using statistical analysis software (JMP [10]). All plots in this paper show mean diamonds, which show the mean value (center line) and 95\% confidence interval of that mean (upper and lower tips). Non-overlapping diamonds represent statistically significant differences in mean values. Mean values were also compared using a Student's t-test with $p$-values $\leq 0.05$ being considered statistically significant. The survey was distributed electronically by the Dean's Office. Participation was strictly voluntary and the participants' identities were confidential. Table 1 shows the number of respondents by degree program and class standing. The number of respondents was balanced except for lower-class ETAC students. This results in a larger confidence interval on the mean for this group (i.e. taller mean diamond). The overall student response rate was $45 \%$ with both program types falling in the $40-50 \%$ range. The response rate was similar to other student surveys that have been sent out in the past. As appropriate and if applicable depending on the learning environment, additional data will be collected in future semesters to monitor student opinion. Tables 2-4 show demographic information on the respondents [11].

Table 1. Student response count by program type (EAC, ETAC) and class (LC, UC)

\begin{tabular}{|r|c|c|c|c|}
\hline Program Type & $\begin{array}{c}\text { LC } \\
\text { \# Responses }\end{array}$ & $\begin{array}{c}\text { UC } \\
\text { \# Responses }\end{array}$ & $\begin{array}{c}\text { Total } \\
\text { \# Responses }\end{array}$ & $\begin{array}{c}\text { Estimated Overall } \\
\text { Response Rate }\end{array}$ \\
\hline EAC (BSE, EE) & 72 & 99 & 171 & $52 \%$ \\
\hline ETAC (ET, ECET) & 26 & 74 & 100 & $42 \%$ \\
\hline
\end{tabular}


Table 2. Gender of Respondents

\begin{tabular}{|l|c|}
\hline Gender & \% \\
\hline Male & 87 \\
\hline Female & 13 \\
\hline
\end{tabular}

Table 3. Ethnicity of Respondents

\begin{tabular}{|l|c|}
\hline Ethnicity & $\mathbf{\%}$ \\
\hline White, Not of Hispanic Origin & 80.4 \\
\hline Asian or Pacific Islander & 4.1 \\
\hline Black, Not of Hispanic Origin & 3.3 \\
\hline Multiracial & 3.3 \\
\hline International / Other & 3.7 \\
\hline Did Not / Refused to Disclose & 5.2 \\
\hline
\end{tabular}

Table 4. Ethnicity of Respondents (Hispanic or Latino Origin)

\begin{tabular}{|l|c|}
\hline Ethnicity & \% \\
\hline Not Hispanic or Latino & 87.4 \\
\hline Hispanic or Latino & 8.9 \\
\hline Did Not Report & 3.7 \\
\hline
\end{tabular}

\section{Data and Analysis}

In the first grouping of questions, EAC and ETAC students responded to four questions about their learning preferences related to overall course format (face-to-face, hybrid, online) and delivery method for online lectures (synchronous, asynchronous), as well as their overall satisfaction with online learning in major courses. Figure 1 shows the format preference (face-toface, hybrid, online) for three different types of classroom activities (labs, lectures, and projectbased). For the purposes of analysis, respondents were grouped by category of major degree program $(\mathrm{E}=$ engineering/EAC, $\mathrm{ET}=$ engineering technology/ETAC$)$ as well as their class standing ( $\mathrm{LC}=$ lower class: freshman and sophomore, $\mathrm{UC}=$ upper class: junior and senior). The extent of all mean diamonds in this paper represents the $95 \%$ confidence interval on the mean. Table 5 shows pairwise comparisons of means within each Course Type that have p-values $\leq$ 0.05 . As expected, students as a whole preferred face-to-face for hands-on activities such as labs and project-based courses. Interestingly, upper-class engineering students (E:UC) were more tolerant of less face-to-face interaction compared to other student groups. This suggests that student maturity, at least for EAC programs, is coupled with learning preference. It is also interesting that this difference is not observed in the ETAC programs which are focused more on application. It should also be noted that throughout the figures below, ET:LC students show a greater variance than other groups. This larger spread is due to smaller sample size, as shown in Table $1(\mathrm{~N}=26$ vs. $72,74,99)$. 
In light of the COVID-19 pandemic, which type

of instruction do you prefer for the following course types?

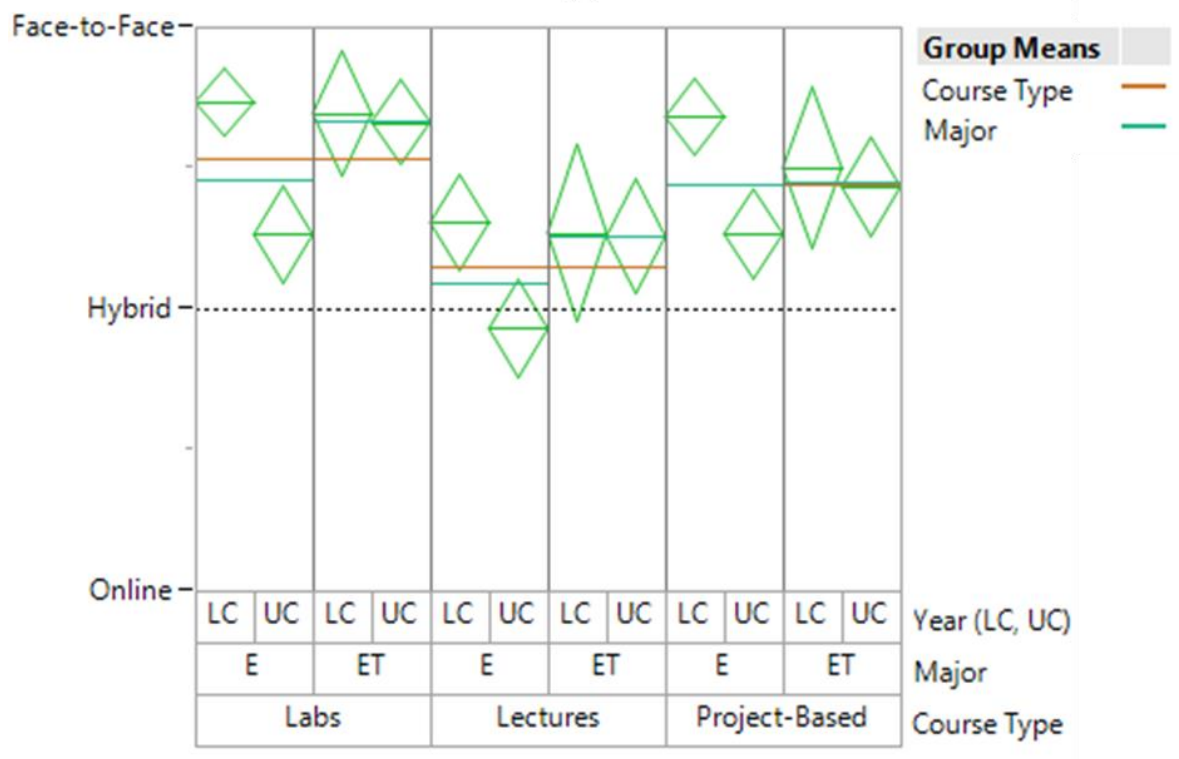

Figure 1. Survey results indicating format preference (face-to-face, hybrid, online) for three different types of classroom activities (labs, lectures, and project-based).

Table 5. Pairwise comparison of means in Figure 1 using Student's t-test for groups within each Course Type.

\begin{tabular}{|l|c|c|c|}
\hline Course Type & Group 1 & Group 2 & P-Value \\
\hline Labs & E:UC & E:LC & $<.0001$ \\
\hline Labs & E:UC & ET:UC & 0.0002 \\
\hline Labs & E:UC & ET:LC & 0.0055 \\
\hline \hline Lectures & E:UC & E:LC & 0.0036 \\
\hline Lectures & E:UC & ET:UC & 0.0106 \\
\hline \hline Project-Based & E:UC & E:LC & 0.0003 \\
\hline Project-Based & ET:UC & E:LC & 0.0394 \\
\hline
\end{tabular}


Figure 2 shows student response to the second question in this group, "I learn well in the given course type" (face-to-face, hybrid, online), using a Likert scale (strongly agree, agree, disagree, strongly disagree). Table 6 shows pairwise comparisons of means within each Course Type that have $\mathrm{p}$-values $\leq 0.05$. The student groups agreed with this statement for face-to-face courses, were neutral for hybrid courses, and three of four student groups disagreed with this statement for online formats. Similar to the first question in this group, upper-class engineering students (E:UC) were slightly more accepting of online formats, with a neutral response to whether they learned well in online courses.

I learn well in the given course type.

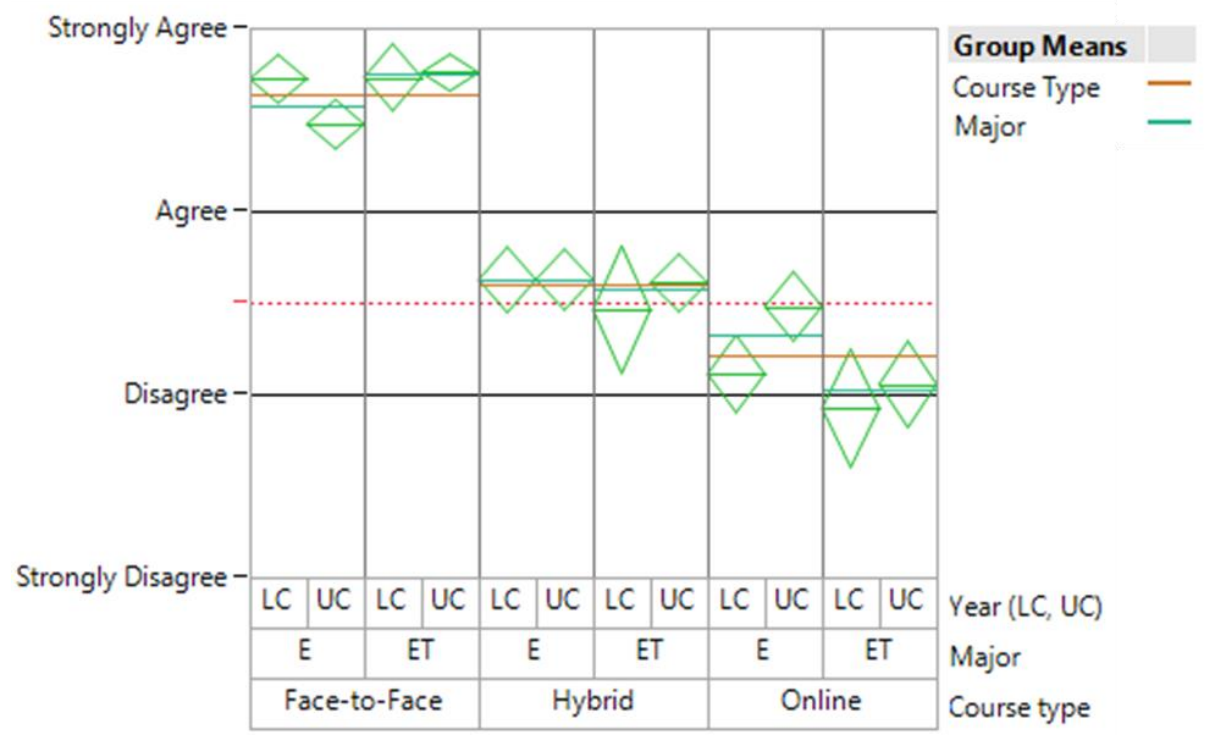

Figure 2. Survey results showing level of agreement with the statement "I learn well in the given course type" for three course types (face-to-face, hybrid, online).

Table 6. Pairwise comparison of means in Figure 2 using Student's t-test for groups within each Course Type.

\begin{tabular}{|l|c|c|c|}
\hline Course Type & Group 1 & Group 2 & P-Value \\
\hline Face-to-Face & E:UC & ET:UC & 0.0014 \\
\hline Face-to-Face & E:UC & E:LC & 0.0052 \\
\hline Face-to-Face & E:UC & ET:LC & 0.0415 \\
\hline Online & E:UC & ET:LC & 0.0078 \\
\hline Online & E:UC & ET:UC & 0.0036 \\
\hline Online & E:UC & E:LC & 0.0122 \\
\hline
\end{tabular}


Figure 3 shows student response to the third question in this group, "If a course must be online, I learn best in which delivery method" (synchronous, asynchronous). Table 7 shows pairwise comparisons of means that have p-values $\leq 0.05$. Engineering technology (ET) students showed equal preference for the two delivery formats while engineering students (E) showed a slight preference for asynchronous delivery. Of the four groups, lower class engineering technology (ET:LC) students showed more of a preference for synchronous online courses, although this group was still neutral on this question (mean diamond overlaps neutral level indicated by red dotted line). It is also interesting that students agreed that they learned well in face-to-face courses (Figure 2), yet for online courses they did not show a strong preference for the synchronous format which would more closely replicate the face-to-face experience. Technology issues and particularly high-speed internet access in rural areas might also play a role in this preference.

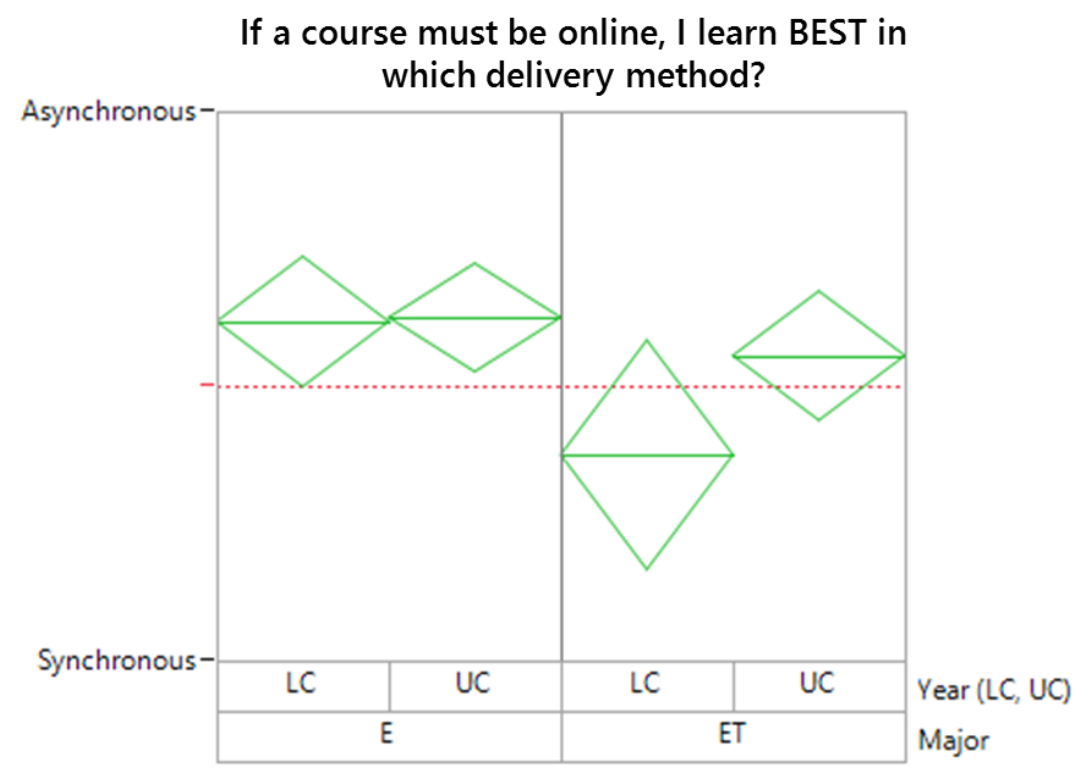

Figure 3. Survey results showing preferred online format (asynchronous, synchronous).

Table 7. Pairwise comparison of means in Figure 3 using Student's t-test.

\begin{tabular}{|c|c|c|}
\hline Group 1 & Group 2 & P-Value \\
\hline ET:LC & E:UC & 0.0268 \\
\hline ET:LC & E:LC & 0.0388 \\
\hline
\end{tabular}


Figure 4 shows student response to the fourth question in this group, "How would you evaluate your online learning experience for courses taken in your major during the current school year." Table 8 shows pairwise comparisons of means that have $p$-values $\leq 0.05$. The four student groups rated their experience between fair and good with the tips of several mean diamonds intersecting the "fair" level. While the goal is to have an excellent learning experience in all formats, these data suggest that students at a rural, regional comprehensive university would prefer and likely benefit from a return to more traditional instruction methods.

How would you evaluate your online learning experience for courses taken in your major (ET, $\mathrm{ECET}$, EE, or BSE prefixes) during the current school year?

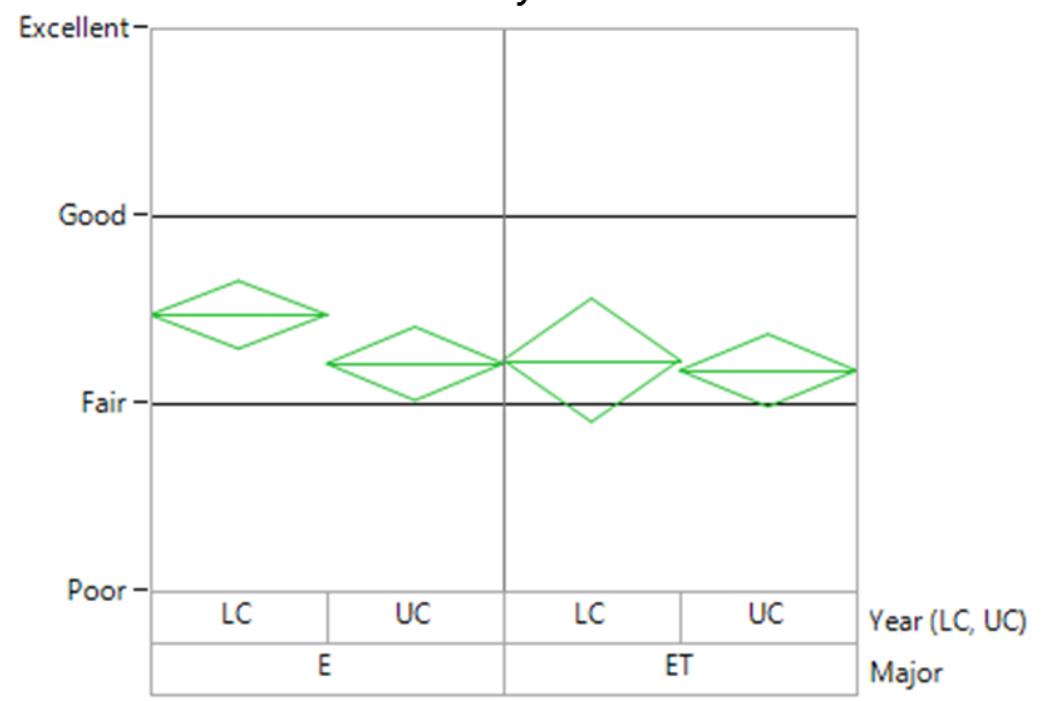

Figure 4. Survey results showing overall student evaluation (excellent, good, fair, poor) of their online learning experience for classes within their major.

Table 8. Pairwise comparison of means in Figure 4 using Student's t-test.

\begin{tabular}{|c|c|c|}
\hline Group 1 & Group 2 & P-Value \\
\hline E:LC & ET:UC & 0.0413 \\
\hline
\end{tabular}


In the second grouping of questions, EAC and ETAC student expectations of instructors and their impressions of instructor behavior were surveyed. Figure 5 shows student expectations for in-person office hours based on their response to the question "I expect my instructors to hold inperson face-to-face office hours" using a Likert scale. Figure 6 shows student impressions of faculty remote work based on their response to the question "I'm OK with the faculty working from home, they do not need to be on campus to serve my academic and advisement needs" using a Likert scale. Tables 9 and 10 respectively show pairwise comparisons of means that have p-values $\leq 0.05$. Both UC groups had lower expectations related to in-person office hours (neutral) and a more positive view of the adequacy of faculty remote work (agree). Both LC groups had higher expectations related to in-person office hours (agree) and a less positive view of the adequacy of faculty remote work (neutral). Overall responses were similar for both engineering and engineering technology students.

I expect my instructors to hold in-person face-face office hours.

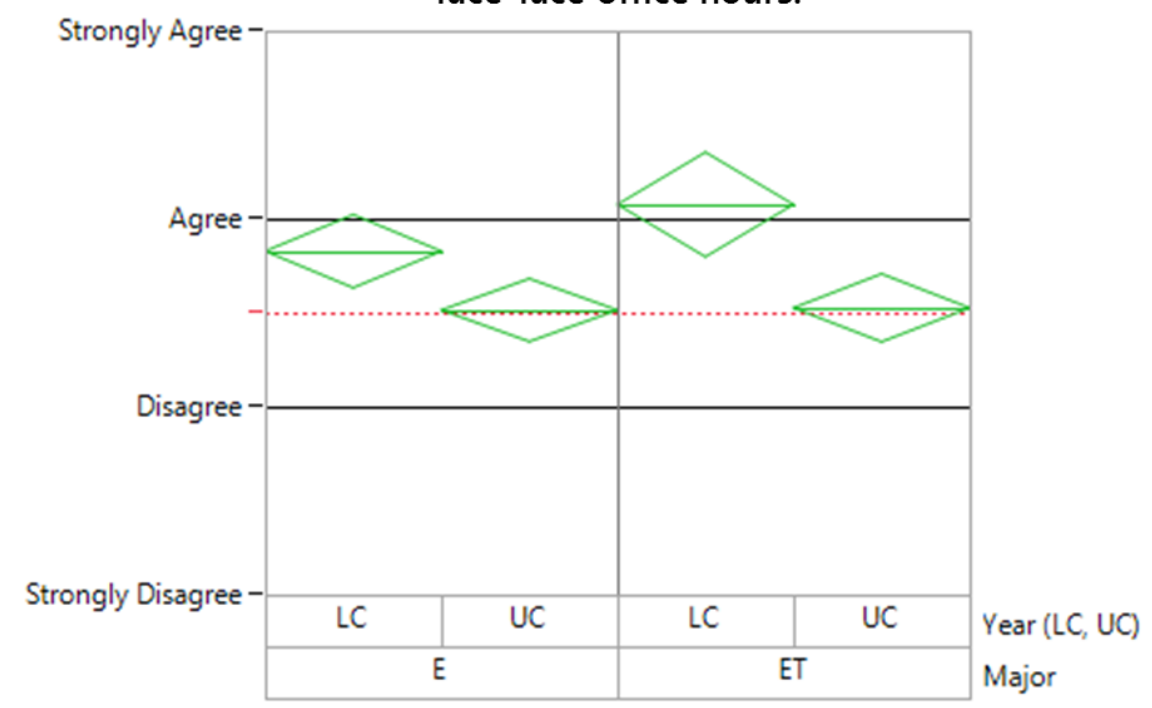

Figure 5. Survey results showing level of agreement with the statement "I expect my instructors to hold in-person office hours" using a Likert scale.

Table 9. Pairwise comparison of means in Figure 5 using Student's t-test.

\begin{tabular}{|c|c|c|}
\hline Group 1 & Group 2 & P-Value \\
\hline ET:LC & E:UC & 0.0017 \\
\hline ET:LC & ET:UC & 0.0029 \\
\hline E:LC & E:UC & 0.0131 \\
\hline E:LC & ET:UC & 0.0252 \\
\hline
\end{tabular}


I'm OK with the faculty working from home, they do not need to be on campus to serve my academic and advisement needs.

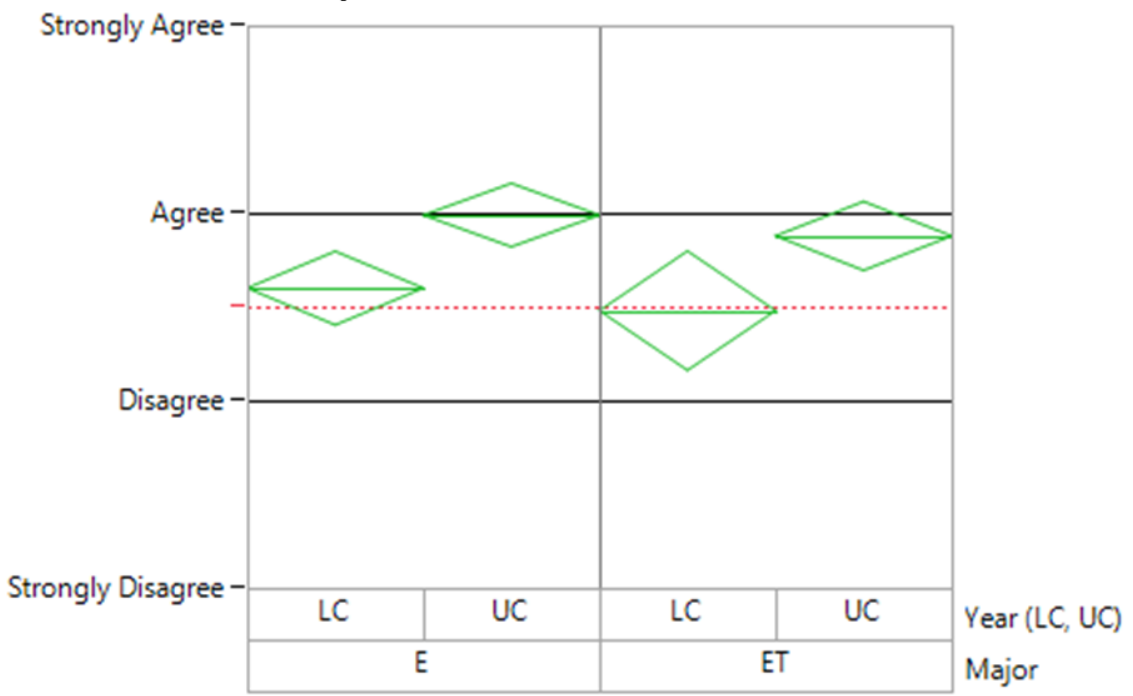

Figure 6. Survey results showing level of agreement with the statement "I'm okay with faculty working from home, they do not need to be on campus to serve my academic and advisement needs" using a Likert scale.

Table 10. Pairwise comparison of means in Figure 6 using Student's t-test.

\begin{tabular}{|c|c|c|}
\hline Group 1 & Group 2 & P-Value \\
\hline E:UC & E:LC & 0.0026 \\
\hline E:UC & ET:LC & 0.0058 \\
\hline ET:UC & ET:LC & 0.0362 \\
\hline ET:UC & E:LC & 0.0422 \\
\hline
\end{tabular}

Figure 7 shows student response to the third question in this group, "In light of the COVID-19 pandemic, to what extent have your instructors exhibited the following behaviors?"

- Had reasonable expectations of students

- Remained positive

- Responded appropriately to needs of students

- Shown care and concern for students

Table 11 shows pairwise comparisons of means within each Instructor Behavior that have pvalues $\leq 0.05$. Most responses fell within the "Some" and "Very Much" levels. Student groups thought instructors had not done quite as well with behaviors related to having reasonable expectations and responding to their needs. The responses from lower-class engineering technology students (ET:LC) overlapped the "Some" level for two instructor behaviors. Overall, the student groups had a positive view of instructor behavior during the COVID-19 pandemic. This reflects well on faculty efforts to adapt and respond to the disruptions in higher education 
caused by COVD-19. Students seem to realize and appreciate that faculty are trying to make the most of a non-ideal situation.

In light of the COVID-19 pandemic, to what extent have your instructors exhibited the following behaviors?

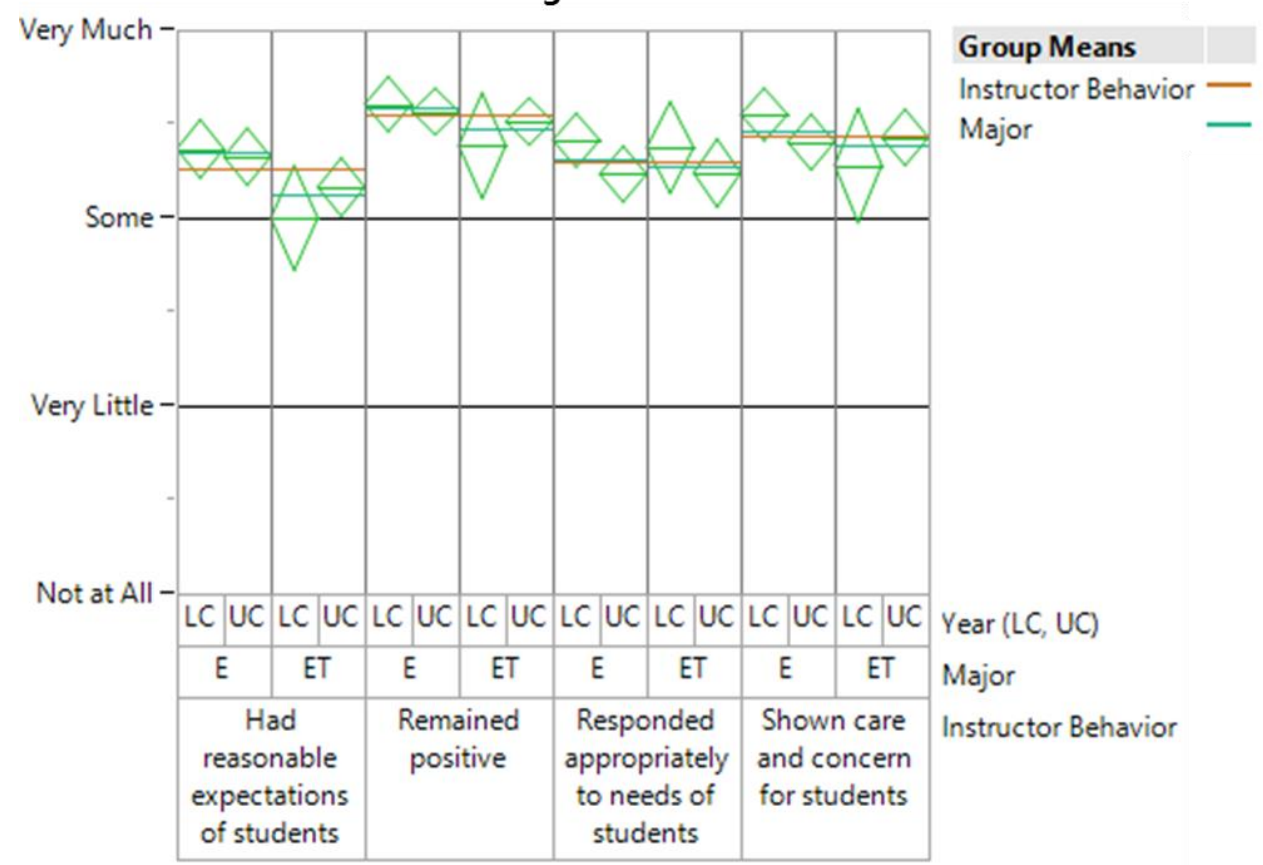

Figure 7. Survey results showing the degree (very much, some, very little, not at all) to which instructors exhibited particular behaviors.

Table 11. Pairwise comparison of means in Figure 7 using Student's t-test for groups within each Instructor Behavior.

\begin{tabular}{|l|c|c|c|}
\hline Instructor Behavior & Group 1 & Group 2 & P-Value \\
\hline Had reasonable expectations & ET:LC & E:LC & 0.0235 \\
\hline Had reasonable expectations & ET:LC & E:UC & 0.0381 \\
\hline
\end{tabular}




\section{Conclusions}

The information that can be drawn from Figure 1 is very interesting. It was not a surprise that students preferred face-to-face learning modalities. Students in both E and ET programs tended to show more acceptance of hybrid content delivery for lecture-type courses, while showing a strong preference for face-to-face interaction in labs and project-based courses. In each of the three formats (labs, lectures, and project-based) E:LC, ET:LC, and ET:UC students had similar preferences, tending toward face-to-face. In contrast, E:UC students showed a greater preference for a hybrid modality. It is believed that this difference is due to academic maturity that develops with juniors and seniors, coupled with theoretical courses that involve less hands-on learning. ET:UC students also have academic maturity, but most of their courses have hands-on content, even those in lecture format.

Results from Figure 2 support the student responses from Figure 1. Overall, they show a very strong preference for face-to-face instruction with neutral results for hybrid, and a disapproval of online formats. These students enrolled in programs that were traditionally taught in face-to-face formats. An abrupt transition to online and then hybrid modalities was not well received. Again, E:UC students tended to be less disagreeable with online instruction. The overall preference for face-to-face instruction is logical given the PBL-centric structure of WCU's programs. When COVID-19 forced courses into hybrid and online modalities, the opportunities for students to learn in hands-on settings were reduced significantly. Furthermore, there is a statistically significant difference between E:UC and ET:UC responses to the online modality, with the engineering technology students showing less preference for online courses. While both have a mix of theory and application, the ET-programs rely more heavily on hands-on experiences than E-programs, especially in the upper-class years where most of the major-specific courses are loaded.

The question about synchronous vs. asynchronous methods is helpful to faculty as they structure future online courses. ET:LC students tended to prefer synchronous delivery, which seems to better approximate face-to-face instruction than asynchronous delivery. ET:LC students benefit more from the direct interaction that a synchronous class offers. It also interesting that all student groups did not show a stronger preference for synchronous online delivery which would seem to better replicate the face-to-face experience. WCU is located in a rural, mountainous region so technology issues such as a lack of access to high-speed internet may also be a factor in student response.

Figure 4 provides overall commentary on the learning experience for all four subgroups of students. The timing of this survey allowed students to experience a half-semester of fully online instruction in Spring 2020 and the initial portion of a hybrid (largely online) semester in Fall 2020. The tendency toward a "fair" experience aligns with most of the sentiments that faculty have received from students. While the goal is to have an excellent learning experience in all formats, these data suggest that students at a rural, regional comprehensive university would prefer and likely benefit from a return to more traditional instruction methods.

Regarding student-faculty relationships, several important conclusions can be drawn from the results of the survey. Overall, students were very approving of efforts made by instructors to adapt to new modes forced by COVID-19, as illustrated by Figure 7. Upper-class students with a 
greater tendency to work in self-directed and independent modes were more agreeable with faculty working from home, as shown in Figure 6. Instructors need to develop modes of interacting with students, particularly lower-class students who need more guidance, during times when online course delivery is necessary.

\section{References}

[1] Stone, W. L., Jack, H., Project Based Learning Integrating Engineering Technology and Engineering. Proceedings of the 2017 American Society for Engineering Education Annual Conference \& Exposition, June 25-28, 2017.

[2] Marinoni, G., Van't Land, H., \& Jensen, T., The impact of Covid-19 on higher education around the world. IAU Global Survey Report, May 2020.

[3] Gardner, L. "Covid-19 has forced higher ed to pivot to online learning. Here are 7 takeaways so far." The Chronicle of Higher Education 20 (2020).

[4] Almatrafi, O, Islam, K., Johri, A, Nagappan, K., Modanlu, A., An Empirical Study of Faceto-Face and Distance Learning Sections of a Core Telecommunication Course.

Proceedings of the 2015 American Society for Engineering Education Annual Conference \& Exposition, June 14-17, 2015.

[5] Balascio, C., Pedagogical Considerations in Use of Online Problem Sets in Technical Courses. Proceedings of the 2017 American Society for Engineering Education Annual Conference \& Exposition, June 25-28, 2017.

[6] Hildebrand, E., Bekki, J., Bernstein, B., Harrison, C., Online Learning Environment Design: A Heuristic Evaluation. Proceedings of the 2013 American Society for Engineering Education Annual Conference \& Exposition, June 26-27, 2013.

[7] Peercy, P., Cramer, S., Redefining Quality in Engineering Education Through Hybrid Instruction. Journal of Engineering Education; Washington Vol. 100, Issue. 4, (Oct 2011): 625-629.

[8] Martinez-Caro, E., Factors affecting students' satisfaction in engineering disciplines: traditional vs. blended approaches. European Journal of Engineering Education, Volume 36,2011 , issue 5 .

[9] National Survey of Student Engagement COVID Module. Retrieved from https://nsse.indiana.edu/nsse/survey-instruments/topical-modules/covid.html on September $20^{\text {th }}, 2020$.

[10] JMP 14 [Computer Software]. https://www.jmp.com/en_us/home.html.

[11] Office of the Registrar (2020). ENG_DR_202080.xlsx Demographic Data Internal Report. Western Carolina University [accessed 11/18/2020]. 